\title{
HACIA UNA RENOVACIÓN DE LA DOCTRINA EN EL DERECHO CIVIL: ESTILO Y CONTENIDOS
}

\author{
Towards a renewal of doctrine in Civil Law: style and contents \\ Verso un rinnovo della dottrina nel Diritto Civile: stile e contenuti \\ Marcelo Urbano Salerno ${ }^{1}$ \\ Para citar este artículo: \\ Salerno, M.U. (2020). "Hacia una renovación de la doctrina en el derecho \\ civil: estilo y contenidos”. Prudentia Iuris, N. Aniversario, pp. 299-308. \\ DOI: https://doi.org/10.46553/prudentia.aniversario.2020.pp.299-308
}

"La atención a las leyes es garantía de inmortalidad". (Libro de la Sabiduría 6-18)

Resumen: Los cambios habidos en el Derecho Privado argentino deben respetar la plenitud del universo jurídico. La labor de la doctrina consiste en indagar el sustento científico de las reformas introducidas en el novísimo Código Civil y Comercial y adecuarlas según el método sistemático. El Derecho está por encima de la legislación y se funda en el orden natural, a fin de perpetuar los valores y los principios que gobiernan a la sociedad.

Palabras clave: Ciencia del Derecho; Nuevo Derecho; Método y técnica; Literatura jurídica; Familia.

Abstract: Changes in Argentine Private Law must respect the fullness of the legal universe. The work of the doctrine consists of investigating the scientific support of the reforms introduced in the newest Civil and Com-

1 Profesor Emérito de la Pontificia Universidad Católica Argentina. Académico titular de la Academia Nacional de Ciencias de Buenos Aires. Correo electrónico: salerno.mu@gmail.com 
mercial Code and adapting them according to the systematic method. Law is above legislation and is based on the natural order, in order to perpetuate the values and principles that govern society.

Keywords: Science of Law; New Law; Method and technique; Legal literature; Family.

Sommario: Le modifiche al Diritto Privato argentino devono rispettare la pienezza dell'universo giuridico. Il lavoro della dottrina consiste nell'indagare il supporto scientifico delle riforme introdotte nel nuovo Codice Civile e Commerciale e adattarle secondo il metodo sistematico. La legge è al di sopra della legislazione e si basa sull'ordine naturale, al fine di perpetuare i valori ei principi che governano la società.

Parole chiave: Scienza del diritto; Nuova legge; Metodo e técnica; Letteratura giuridica; Famiglia.

Una interpretación exegética de la Sagrada Escritura ${ }^{2}$ permite afirmar que el conocimiento es la cualidad de los seres humanos desarrollada por la educación y por la experiencia. Sirva el epígrafe de las siguientes notas para introducir al lector en el nuevo Derecho que se está gestando desde mediados del siglo XX hasta la actualidad. En ese lapso transcurrido, la legislación fue modificando paulatinamente las instituciones que surgieron luego de la Organización Nacional (1853/1860), después de ser sancionados los Códigos Civil (1869) y Comercial (1889), dos cuerpos legales que han sido abrogados y sustituidos por otro "corpus", que los unificó en un novísimo texto (2014).

En nuestro tiempo, que es el tiempo de sembrar las semillas de los frutos a cosechar, ha llegado el momento en el que la doctrina se renueve a partir de la vigencia del Código Unificado en el año 2015. Se plantea, pues, el interrogante de cuál tendrá que ser el método apropiado a esa tarea, la técnica más adecuada, el contenido de los trabajos a emprender, y el estilo de los comentarios a las normas en vigor.

Asistimos a la elaboración de teorías innovativas a raíz de los cambios efectuados a las figuras jurídicas tradicionales, los que han creado construcciones distintas a las existentes, mediante pautas de interpretación basadas en principios innovadores, como ser acerca de la ampliación de las facultades del Juez. Nadie puede negar la transformación habida en nues-

2 Alisejo, S. (1963). Diccionario de la Biblia. Barcelona. Edit. Herder, 1742. 
tro ordenamiento, como tampoco se puede sostener que el Derecho común o legislación de fondo haya perdido su raíz científica. La mejor manera de enfocar la realidad existente es asumir que el novísimo Código Civil y Comercial Unificado introduce reformas sustanciales para la vida en sociedad de los habitantes del país. Mas ello no es suficiente, ya que cualquiera fuese la modificación habida, esta tiene que sustentarse en la ciencia del Derecho, labor a cargo de la doctrina que cabe destacar.

Las circunstancias históricas son determinantes para introducir los cambios necesarios en la sociedad por una multiplicidad de causas; entonces, se impone una revisión, dado que las condiciones económicas y sociales son diferentes a las del pasado. Esos cambios, que obedecen al principio de la evolución, no pueden contradecir los fundamentos del orden social existente, ni desmerecer los principios que hicieron a la formación moral e intelectual de una Nación. Cuando llega la hora de cosechar se comprobarán los resultados obtenidos y será entonces la oportunidad de evaluar si reportaron beneficios para afianzar la Justicia.

Un fenómeno digno de ser mencionado es el que surgió en Francia después de la Primera Guerra Mundial (1914 a 1918). Finalizada la contienda, los autores advirtieron que debían encarar las transformaciones habidas en la legislación francesa dictada al margen del Código Civil, según los principios generales del Derecho. Marcel Planiol escribió al respecto que el legislador debía orientarse hacia la equidad, inspirado en el Derecho Natural, que es la regla suprema ${ }^{3}$; regla que tiene mayor jerarquía en el ordenamiento. En esa época, Francois Gény publicó la segunda edición de su famosa obra, Méthode d'interpretation et sources en droit privé positif. Essai critique (año 1919), ampliada en dos tomos, obra en la cual su autor desarrolló la célebre teoría científica del Derecho, tras el ocaso de la escuela de la exégesis ${ }^{4}$.

La experiencia habida en las sociedades sobre la incorporación de modificaciones a su ordenamiento institucional, permite apreciar cómo operaron esos cambios, manteniendo numerosos enunciados generales que permanecieron inmutables. Uno de los acontecimientos políticos más importantes de las últimas décadas, en ese sentido, fue la caída del Muro de Berlín, y el retorno de los países de Europa del Este al sistema romano germánico del

3 Planiol, M. (1920). Traité Élémentaire de Droit Civil. T. I. 8ª ed. París, 2-3. Este autor pensaba que era inútil una revisión general del "Code Civil"; una ordenanza dictada en el año 2016 modificó el régimen contractual francés.

4 Salerno, M. U. (2007). "La costumbre en el pensamiento de Francois Gény". En Anuario de Filosofía Jurídica y Social. Buenos Aires. Asociación Argentina de Derecho Comparado. Abeledo Perrot, $n^{\circ}$ 27, 71-73. Gény también aludió a "la naturaleza de las cosas", según las condiciones naturales y biológicas, como un elemento imprescindible del sistema jurídico. 
Derecho Privado. Este hecho histórico demuestra cómo los pueblos ${ }^{5}$ socialistas que habían estatizado los medios de producción, abolido la propiedad privada, y prohibido la libre contratación, dictaron nuevos códigos en lo civil según los principios clásicos anteriores a la vigencia del comunismo. Algo similar también ocurrió en la Federación Rusa a partir de 1993, aunque con algunas variantes. Súmase a ello la reunificación de Alemania en el año 1990, determinando la aplicación en todo su territorio del BGB (Bürgerliches Gesetzbuch) vigente en la República Federal alemana desde el año $1900^{6}$. De ahí entonces que la doctrina hubo de ser renovada por completo en esas naciones, a fin de analizar y describir los nuevos institutos que reemplazaron a las directivas soviéticas que habían subordinado el Derecho a la política revolucionaria del marxismo.

Además, merece ser considerada la reforma que hicieron tres Estados sudamericanos para adecuar el Derecho Privado a las corrientes vigentes en la actualidad; esos Estados son Argentina, Brasil y Paraguay. Los novedosos códigos de esos países unificaron las ramas civil y comercial en un mismo cuerpo. Se los ha calificado de responder a una tendencia ecléctica ${ }^{7}$, como también se reconoció -al menos en nuestro caso- que es una elaboración académica, basada en la doctrina y la jurisprudencia ${ }^{8}$. Se tiene que poner énfasis en este último punto, dado que existe un reconocimiento a la labor cumplida anteriormente por los juristas en torno a los Códigos Civil y Comercial abrogados y sus respectivas fuentes. De modo tal que no ocurrió una ruptura en la línea doctrinaria, sino que se la puede continuar aplicando siempre que sea compatible con la reforma.

La labor científica a emprender por los autores nacionales ante el Código de 2014 consistirá ahora en estudiar las innovaciones realizadas para ajustarlas a la realidad. Esa tarea intelectual requerirá descubrir las ideas rectoras que gobiernan a ese conjunto normativo, y explicar sus principios explícitos e implícitos. Ello significa la recreación de las normas, más allá de su literalidad, para orientarlas hacia los fines perseguidos por el legislador y, de ese modo, valorar su mérito.

5 Ganbaro, A.; Sacco, R. y Vogel, L. (2011). Le droit de l'Occident et d'ailleurs. París. Edit. LGDJ, 342-348.

6 Fromont, M. (2009). Grands systemes de droit étrangers. $6^{\mathrm{a}}$. ed. París. Edit. Dalloz, 22-23 y $32-39$.

7 David, R.; Jauffret-Spinossi, C. y Goré, M. (2016). Les grands systemes de droit contemporains. $12^{\mathrm{a}}$. ed. París. Edit. Dalloz, $\mathrm{n}^{\circ}$ 63, 62-63.

8 Limodio, G. (junio 2016). "El título preliminar del Código Civil y Comercial como núcleo de significaciones”. En Prudentia Iuris nº 81, Buenos Aires, Educa, 22; el autor destaca que dicho título comprende nociones sobre el Derecho y acerca de la ley. 
Con motivo de la reforma de la Constitución, a partir del año 1994 la doctrina asumió sistematizar las normas sobre las relaciones de familia a fin de implementarlas a casos concretos (art. 75, incisos 19 y 23, CN). Debido a esa reforma se estableció una triple conexión entre tres ramas jurídicas: el Derecho Constitucional, el Derecho Internacional, y el Derecho Privado. La familia es el punto de conexión entre las tres ramas mencionadas, alrededor de las cuales giran principios éticos con jerarquía superior. Son enunciados de validez universal, diseminados en convenciones aplicables imperativamente en el novísimo Código Civil y Comercial. Todo ser humano merece disfrutar de una vida familiar plena, en aras a su honra y dignidad, de manera que los intérpretes habrán de armonizar el "corpus" con las garantías constitucionales incorporadas al ordenamiento hace más de dos décadas. Es el ámbito de la privacidad, el refugio afectivo de las personas en su vida íntima, donde tienen su hogar ("Oikos", para los griegos); ámbito inviolable que pertenece al orden privado.

En la antigüedad ya se habían distinguido tres elementos formativos del Derecho: la ley, la jurisprudencia y la doctrina. Pero en Roma, durante la República (años 509 a 27 a.C.), regía en una instancia superior la costumbre tradicional ("mores") con el control del Pontífice". En esa época las leyes eran excepcionales y se dictaban en los plebiscitos para impedir injusticias y abusos del Derecho, mientras que la jurisprudencia fijaba la interpretación de la normativa. La ley de citas de autoridad (año 426) rubricó la misión de los juristas Gayo, Papiniano, Paulo, Ulpiano y Modestino, cuyas numerosas obras eran las únicas que tenían validez para la hermenéutica. Es un precedente sobre la valía que tienen las opiniones de los jurisconsultos a fin de que los magistrados funden sus fallos.

Resulta innegable la importancia que siempre tuvieron las escuelas de Derecho en la formación de los abogados desde la antigüedad, tanto en el Imperio Romano de Occidente, como el de Oriente. En la escuela de Beirut ("Berito"), fundada en el año 239, enseñaron grandes maestros. A partir del siglo XI surgió en la ciudad de Bolonia un centro dedicado a la enseñanza del Derecho romano justinianeo, donde se formaron los glosadores y los posglosadores para idear el "mos italicus". Esos estudios contribuyeron a difundir las obras clásicas -como las Institutas, de Gayo-, adoptaron el método exegético y enunciaron adagios o brocardas ${ }^{10}$ en breves frases.

9 Di Pietro, A. (2007). "La costumbre en el Derecho romano". Anuario de Filosofía Jurídica y Social. Asociación Argentina de Derecho Comparado. Buenos Aires. Abeledo Perrot, $\mathrm{n}^{\circ}$ 27, 43-44.

10 Koschaker, P. (1955). Europa y el Derecho romano. Madrid. Edit. Revista de Derecho Privado, en p. 2 escribió: "[...] la Escuela de los Glosadores de Bolonia siempre ha sido como la piedra angular de la construcción que llamamos Europa”. 
Los antecedentes mencionados demuestran que la doctrina ha tenido una influencia notoria en la evolución del Derecho, al que aportó las nociones fundamentales que subsisten hasta el presente.

Según la perspectiva científica, el Derecho es la suma de los conocimientos necesarios para comprender el sistema jurídico, conocimientos que se transmiten en la Universidad, donde se enseña la disciplina específica, más los elementos de las disciplinas auxiliares. Si no se parte de esta premisa, se incurre en lo superficial y ambiguo, sin la posibilidad de obtener las soluciones adecuadas a los problemas concretos que se presentan en la vida comunitaria. Si se toma un camino erróneo no se llega a destino y, lo que es peor, se pierde la razonabilidad para orientar la conducta debida. Por tanto, hay que desvirtuar los elementos irracionales y disociadores que contaminan y corrompen el funcionamiento regular de las instituciones.

Desde la Universidad llegan las ideas que nutren al pensamiento jurídico en cada etapa histórica; es una constante que se pone en evidencia en la dinámica generacional de los juristas. Ayer se discutía sobre la conveniencia de la codificación, tiempo después el debate se circunscribiría a la interpretación de las normas, más tarde nacerían novedosos institutos que migraron de otros países. Pero el núcleo de las discusiones, el escenario donde se ventilan las controversias a un nivel superior al común, son las aulas universitarias. Esto puede ser resumido en los siguientes términos: cátedra y vida.

Por ello, hay que detenerse en un tema trascendente: el plan de estudios de la carrera de abogacía. Cuando el Deán Gregorio Funes asumió, en el año 1808, el cargo de Rector de la Universidad Mayor de San Carlos en Córdoba, decidió reorganizar la "curricula mentis" de esa Alta Casa. Según el historiador Roberto Peña, luego de acontecida la Revolución de Mayo, el Deán Funes "introdujo las ideas pedagógicas de la época y el espíritu de su siglo"11. El estudio de la ciencia jurídica experimentó una profunda renovación a partir de la sanción en 1869 del Código Civil (Ley N 340).

En la Universidad de Buenos Aires la enseñanza del Derecho Privado en sus orígenes puede dividirse en tres períodos: el denominado "salamantino", anterior a la sanción del Código Civil (1822 a 1872); el inmediatamente posterior a la sanción de dicho cuerpo legal (1872 a 1910); y el período en que la enseñanza se impartió sobre la base de un contenido científico, gradual y sistemático (1910 a 1942); en este último lapso se superó a la escuela francesa de la exégesis y se expuso el Derecho Privado conforme a

11 Peña, R. (1958). El pensamiento político del Deán Funes. Universidad Nacional de Córdoba, 56. 
un método racional ${ }^{12}$. Entonces la doctrina encaró la investigación en esta última dirección. Coincidió el inicio de esta etapa con la vigencia del BGB en Alemania y su posterior divulgación en nuestro país; esta etapa finalizó con la sanción, en Italia, del nuevo Código Civil en 1942, el cual despertó entusiasmo en algunos juristas argentinos.

El aumento de las Facultades de Derecho habido en nuestro país, resultado de la demanda de los estudiantes y las consiguientes decisiones políticas de los gobiernos, determinó la proliferación de autores e investigadores. La fundación de la Universidad Nacional de La Plata en el año 1905, la cual era antes provincial (año 1890), y de la Universidad Nacional del Litoral en el año 1919, que había sido provincial (año 1889), produjeron una apertura de centros de enseñanza jurídica en esos dos lugares claves del interior, a los que luego se sumaría la Universidad Nacional de Tucumán. En cuanto a las universidades privadas se refiere, los títulos que expedían no tuvieron reconocimiento oficial hasta el año 1958. Durante la presidencia de Arturo Frondizi fue sancionada la Ley $\mathrm{N}^{\circ} 14.557$, que dio validez a los títulos académicos de dichas casas de Altos Estudios, como la Pontificia Universidad Católica Argentina, consagrada a formar a estudiantes mediante un claustro de profesores con dotes pedagógicas para la defensa de los valores cristianos ${ }^{13}$.

Disiento de Norberto Bobbio al escribir: "[...] no se le ha atribuido derecho de ciudadanía al jurista, quien expresa opiniones que tanto el legislador como el juez pueden tener en cuenta, pero sin emitir nunca juicios vinculantes ni para el legislador ni para el juez"14. La lectura aislada de este párrafo pareciera descalificar a la doctrina como fuente del Derecho, sin considerar, cuando la opinión es uniforme entre diversos tratadistas de prestigio, quiénes coinciden en torno a una cuestión específica. En el régimen judicial argentino está consagrada la doctrina de los fallos plenarios de los Tribunales

12 Salerno M. U. (1974). "Aporte de Héctor Lafaille a la enseñanza del Derecho Civil". En Revista de Historia del Derecho $\mathrm{n}^{\circ} 2$. Buenos Aires. Instituto de Investigaciones de Historia del Derecho, 199-224. Lafaille, H. (1921). Apuntes de Derecho Civil. T. I. Buenos Aires, p. 3, dice que "el método racional fue implantado por la escuela histórica desarrollado por Savigny y claramente expuesto por Capitant".

13 El Decreto $\mathrm{N}^{\circ} 14.397 / 1959$ autorizó a la UCA a funcionar con el régimen de dicha ley. Se debe destacar que el nuevo plan de estudios de la carrera de abogacía aprobado para esta Facultad incorporó asignaturas de carácter cultural, junto a las denominadas materias codificadas; la finalidad perseguida es ampliar el horizonte intelectual de los futuros abogados y dotarlos de conocimientos imprescindibles en disciplinas extra normativas que enriquezcan su formación personal, en particular en temas de deontología.

14 Bobbio, N. (1998). Teoría general del Derecho. Madrid. Edit. Debate, 245. Este autor italiano funda su teoría - no así su filosofía- en que "la experiencia jurídica es una experiencia normativa". 
Superiores, cuyo acatamiento es obligatorio. A ello corresponde añadir que el Derecho está por encima del legislador, quien no es omnipotente, sin tener la magia de poder cambiar por su sola voluntad el statu quo de una Nación. No es solo en la norma, o en el conjunto de disposiciones, donde el juez encontrará la solución justa y equitativa para fundar su pronunciamiento. En efecto, el nuevo Código Civil y Comercial Unificado, en el Capítulo 1 de su Título Preliminar, se refiere a las atribuciones que tienen los jueces para resolver los casos conforme a Derecho mediante una "decisión debidamente fundada" (art. $\left.3^{\circ}\right)^{15}$. En ese sentido, resulta ineludible la lectura de trabajos de doctrina vinculados con el tema a decidir y la consulta de obras calificadas.

De ese modo, tanto los magistrados, como los letrados se introducen en la literatura jurídica, que tiene una terminología peculiar y un estilo propio. Estamos en presencia de un género literario específico del mundo del Derecho, cultivado por los autores a fin de expresar su pensamiento en torno a los códigos, las leyes, y demás disposiciones normativas. Algunos abogados han sido célebres escritores, como lo fue Santo Tomás Moro, pero por lo general son profesores universitarios o graduados que tienen vocación firme para escribir el resultado de sus investigaciones, como ocurre con los doctores en jurisprudencia, que publican la tesis que les permitió acceder al título máximo ${ }^{16}$. Lo cierto es que en este género domina la prosa discursiva cuya sintaxis está destinada a armar las ideas a sostener y a describir metódicamente el instituto objeto de análisis. Se trata de aplicar el entendimiento para conocer la ley, en sentido amplio, y poder ir más allá del texto, como decía Gény.

El ensayo es la categoría usual para escribir sobre un tema jurídico. Puede ser abstracto, sin otra finalidad que describir la función que cumple un instituto; o bien casuístico, refiriéndose a los problemas concretos que se han planteado en la jurisprudencia. Los tratados presentan características particulares, debido al afán de abarcar la totalidad de un régimen jurídico específico, como además intentar describir toda una rama del Derecho (cito a modo de ejemplo el Tratado de Derecho Civil, de Guillermo Borda). En cambio, los artículos que se publican en revistas especializadas suelen ser

15 López Mesa, M. (2019). Código Civil y Comercial de la Nación. Comentado. Anotado. T. I. $1^{a}$ ed. Buenos Aires. Edit. Hammurabi, 136-140. La obligatoriedad de fundamentar las sentencias judiciales se remonta al año 1838, año en que fue impuesta al Tribunal de Recursos Extraordinarios de Buenos Aires.

16 Castán Vázquez, J. M. (enero/marzo 1999). "El lenguaje jurídico en España y en la República Argentina". Revista del Notariado, $\mathrm{n}^{\circ}$ 855, 35-36, deseaba "que los juristas argentinos continúen conservando en la teoría y en la práctica del Derecho el clásico y depurado lenguaje de las generaciones anteriores". 
el resultado de una investigación previa sobre un asunto controvertido en el Derecho, aunque algunos de esos trabajos se limitan a resumir distintas opiniones. Siempre, cualquiera sea la producción intelectual, requiere seguir un método, sistematizar la materia considerada dentro del ordenamiento, utilizar tecnicismos específicos de la disciplina y la terminología apropiada. Para persuadir a los lectores hay que honrarlos con estilo. Actualmente, se advierte la tendencia a considerar cuestiones interdisciplinarias, como las vinculadas con la economía, la salud, el medio ambiente, la psicología, entre otras ciencias. Lo más importante consiste en desear que los autores ubiquen su escrito dentro del panorama completo de las ramas del Derecho, a fin de respetar la plenitud del universo jurídico.

En suma, el escritor utiliza la palabra a fin de expresar su manera de pensar y describir la construcción jurídica que hubiese realizado. Mediante la palabra transmite el mensaje que ilumina su escritura, porque el idioma es el soporte y el vector del Derecho. Lenguaje y Derecho, coordinados entre sí, hacen a la labor creadora, sobre todo en la hermenéutica de la que se ocupan no solo los filólogos, sino también los filósofos. Suelen existir discusiones entre los juristas sobre esa relación que no parece ser muy armónica; se han suscitado debates en torno a una definición determinada, y alrededor de los conceptos empleados, debates que fueron esclarecedores en muchos sentidos (v. gr., el concepto de empresa). De ahí que el autor tiene que tener un dominio de las leyes sobre las que escribe y un conocimiento preciso de los términos que emplea; de ese modo ganará en claridad y podrá descifrar los enigmas encerrados en neologismos que todavía carecen de carta de ciudadanía.

El contacto con la realidad es el secreto de la doctrina bien elaborada. Desde esa óptica advertimos que en momentos como los actuales, donde la legislación es mutante, y los códigos cambian o están por ser reformados (v. gr., el Código Penal y los Códigos Procesales afines a dicho cuerpo y a las ramas civil y comercial), la doctrina tiene que evolucionar en la medida de sus posibilidades, a fin de orientar a la jurisprudencia. La teoría debe adaptarse paulatinamente a las transformaciones en curso, buscando las palabras que representan los símbolos de los cambios habidos. Una fina percepción de las circunstancias, o según se dice ahora del contexto, hará posible captar la trascendencia de las modificaciones habidas con la plétora de leyes dictadas en los últimos años. Pero además, es necesario pensar los cambios desde la perspectiva de los valores y principios en juego.

Será la Universidad la institución que formará a los futuros juristas a quienes se confía la labor a emprender. Y la esencia de la Universidad está dada por la misión social que cumple en transmitir conocimientos para saber la verdad que se asienta en sólidos pilares a través de los siglos. Le cabe a la doctrina de ayer, de hoy y de siempre, servir a esa finalidad en aras del bien común. Así lo exige la ciencia jurídica. 


\section{MARCELO URBANO SALERNO}

\section{Bibliografía}

Alisejo, S. (1963). Diccionario de la Biblia. Barcelona. Edit. Herder.

Bobbio, N. (1998). Teoría general del Derecho. Madrid. Edit. Debate.

Castán Vázquez, J. M. (enero/marzo 1999). "El lenguaje jurídico en España y en la República Argentina”. Revista del Notariado, nº 855.

David, R.; Jauffret-Spinossi, C. y Goré, M. (206). Les grands systemes de droit contemporains. $12^{\mathrm{a}}$. ed. París. Edit. Dalloz, nº 63.

Di Pietro, A. (2007). "La costumbre en el Derecho romano", Anuario de Filosofía Jurídica y Social. Asociación Argentina de Derecho Comparado. Buenos Aires. Edit. Abeledo Perrot, $\mathrm{n}^{\circ} 27$.

Fromont, M. (2009), Grands systemes de droit étrangers. $6^{a}$. ed. París. Edit. Dalloz.

Ganbaro, A.; Sacco, R. y Vogel, L. (2011). Le droit de l'Occident et d'ailleurs. París. Edit. LGDJ.

Koschaker, P. (1955). Europa y el Derecho romano. Madrid. Edit. Revista de Derecho Privado.

Lafaille, H. (1921). Apuntes de Derecho Civil. T. I. Buenos Aires.

Limodio, G. (junio 2011). "El título preliminar del Código Civil y Comercial como núcleo de significaciones". En Prudentia Iuris n ${ }^{\circ} 81$.

López Mesa, M. (2019). Código Civil y Comercial de la Nación. Comentado. Anotado. T. I. $1^{a}$ ed. Buenos Aires. Edit. Hammurabi.

Peña, R. (1958). El pensamiento político del Deán Funes. Universidad Nacional de Córdoba.

Planiol, M. (1920). Traité Élémentaire de Droit Civil. 8ª ed. París.

Salerno, M. U. (1974). "Aporte de Héctor Lafaille a la enseñanza del Derecho Civil”. En Revista de Historia del Derecho $\mathrm{n}^{\circ} 2$. Buenos Aires. Instituto de Investigaciones de Historia del Derecho.

Salerno, M. U. (2007). "La costumbre en el pensamiento de Francois Gény”. En Anuario de Filosofía Jurídica y Social. Asociación Argentina de Derecho Comparado. Buenos Aires. Edit. Abeledo Perrot. 